\title{
Legionella and risk management in hospitals-A bibliographic research methodology for people responsible for built environment and facility management
}

\author{
Thomas W. Leiblein ${ }^{\mathrm{a}, *}$, Matthew Tucker ${ }^{\mathrm{a}}$, Mal Ashall ${ }^{\mathrm{a}}$, Susanne B. Lee ${ }^{\mathrm{c}}$, \\ Carsten Gollnisch ${ }^{\mathrm{d}}$, Susanne Hofer ${ }^{\mathrm{b}}$ \\ a Liverpool John Moores University (LJMU), Faculty of Engineering and Technology, Department of the Built Environment, Byrom Street, Liverpool L3 3AF, \\ United Kingdom \\ b Zurich University of Applied Sciences (ZHAW), Department Life Sciences and Facility Management, Institute of Facility Management, Grüental, 8820 \\ Wädenswil, Switzerland \\ ${ }^{c}$ Leegionella Ltd., Registered Office, 5 Ribblesdale Place, Preston PR1 8BZ, United Kingdom \\ ${ }^{\mathrm{d}}$ Hygieneinspektionsstelle für Trinkwassersysteme, Hauptring 35, 04519 Rackwitz, Germany
}

\section{A R T I C L E I N F O}

\section{Article history:}

Received 29 April 2016

Received in revised form 27 June 2016

Accepted 1 July 2016

\section{Keywords:}

Facility management

Hospital

Legionella

Water

Risk management

\begin{abstract}
A B S T R A C T
An ongoing research project investigates the roles and duties of persons responsible for the built environment with respect to risk management of water systems and Legionella prevention from a facility management's perspective. Our literature review provides an approach for selecting and analysing abstracts of initially 177 journal articles, subjected to certain topic-specific inclusion and exclusion criteria. Different decision strategies of either logic 'yes/no', Boolean operators 'OR' or 'AND' and decisions for single counts or cumulative counts of the identified three principal keywords 'Legionella', 'hospital' and 'water', were completed. A final list of ten principal reference articles from 29 journals was compiled. It suggests that the interconnected perspective of water systems, Legionella and hospitals seems to be underrepresented in the field of the built environment and facility management. The term 'stakeholder', which would refer to decision-makers, was not found more than once. Our result is a useful summary of established sources of information on environmental Legionella research. The results can be helpful for those new to the topic.
\end{abstract}

(c) 2016 Elsevier GmbH. All rights reserved.

\section{Introduction}

The purpose of this paper is to present a literature review strategy and the results of a combined search and analysis procedure applied to an ongoing research project: Legionella and water systems in healthcare (HC) facilities-a framework for the built environment and implications for facility management (FM). The aim of the research project is to systematically uncover the present situation of Legionella prevention of water systems in selected HC organisations in different countries. It contributes to developing out a 'reference system' guiding people responsible in HC organisations to identify, understand and properly take action for prevention. Merely complying with existing legislation and guidance does not necessarily mean that a system is safe or operates reliably.

\footnotetext{
* Corresponding author.

E-mail address: T.W.Leiblein@2014.ljmu.ac.uk (T.W. Leiblein).
}

An important novel aspect of the research project is taking a FM perspective considering FM and facility services (FS) related aspects of business organisation, processes and legal aspects (Hungenberg, 2014).

To better understand different roles and duties on the prevention of Legionella in water systems within an HC organisation at present, a comprehensive literature review was seen to be mandatory. For that, publications were searched and analysed with respect to an already elaborate research design. Epidemiological and environmental aspects were also taken into account.

The methodological approach of defining a search and analysis strategy to develop a concise literature review not only supports the ongoing research project mentioned above, but will also provide orientation for FM specialists who may be interested in relevant aspects of Legionella risk management. It is interesting especially for those, who are new to the topic or who seek for deeper knowledge or understanding of interdisciplinary efforts. 
Four fundamental dimensions were defined to be considered simultaneously, as shown in the research project design (Fig. 1). These four dimensions provide a framework for the study, representing the idea behind the research project, and provide selection criteria for journals and journal articles. The four dimensions have been characterized in a previous publication, which emphasized the context of the research project (Leiblein et al., 2015). They are summarised below:

\subsection{Legionella}

- Colonization of water systems/waterlines in buildings and associated systems.

- Existing standards, national legislation and guidance.

- Surveillance schemes.

- Amplification of Legionella may be favoured by technical factors like temperature or stagnation (Hoebe and Kool, 2000; Völker et al., 2016).

\subsection{Hospital}

- Complex types of buildings.

- Organisational structures, stakeholders, interdisciplinary work.
- Demands regarding hygienic quality of water and infection prevention.

- Risks arising from built environment, e.g. water systems.

\subsection{Risk management}

- Provision of prevention strategies; preparedness for legal conformity.

- Revised (international) standards.

- Mandatory hazard analysis.

- Technical, structural and organisational levels to meet strategic and operative goals.

\subsection{FM/built environment}

- Covers roles of normative, strategic and operational levels (EN, 2006).

- FM adds value to an organisation whilst fulfilling non-core business tasks of clients (EN, 2006; Gerber and Läuppi, 2015).

- Involved in the management of systems, maintenance and service processes.

In the hospital environment, several stakeholders work in a complex and interdisciplinary $\mathrm{HC}$ setting. Duties and

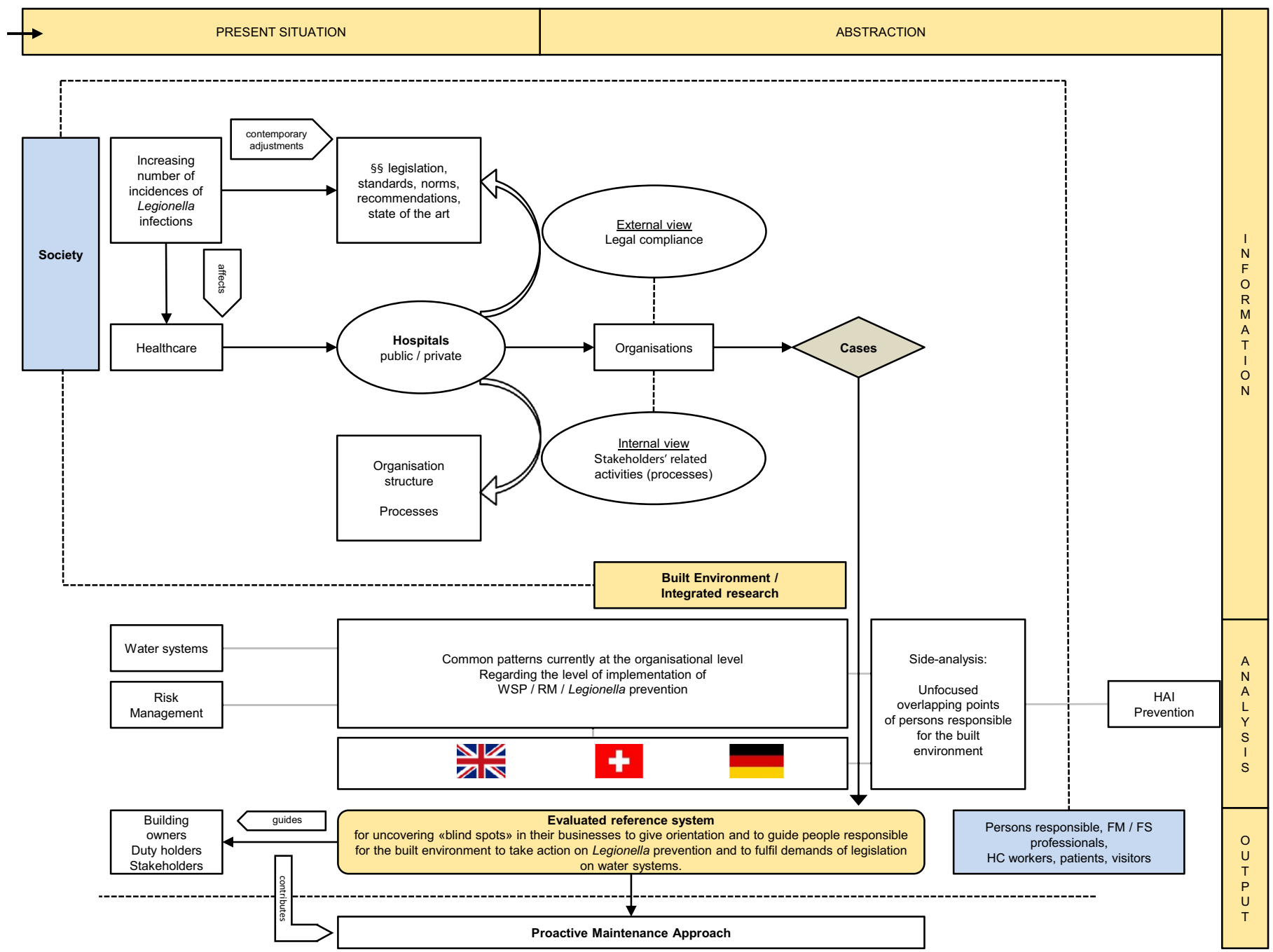

Fig. 1. Research project design and contextual framework. 


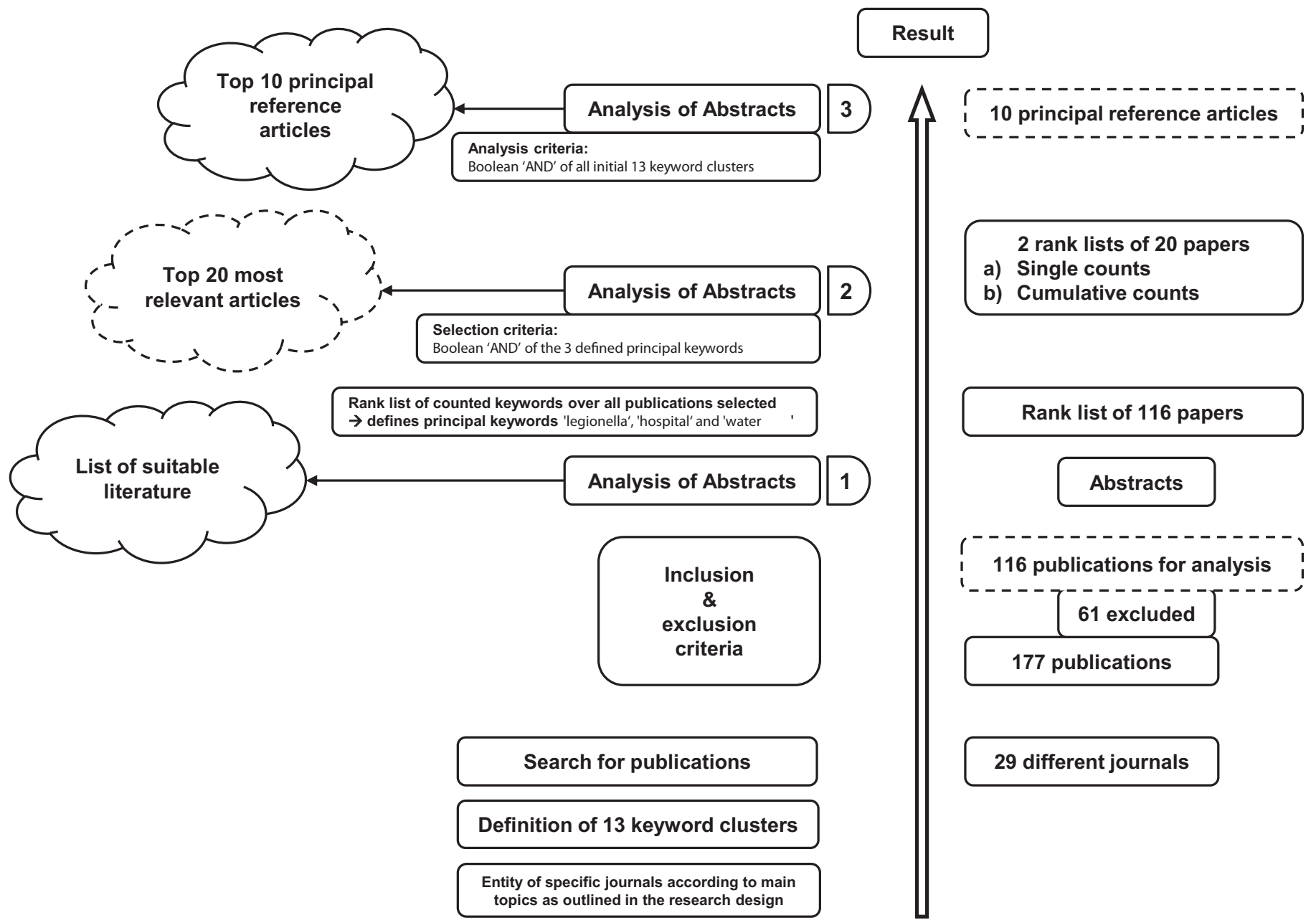

Fig. 2. Illustration of incremental search, selection and analysis of publications relevant for a research project.

responsibilities towards third parties with respect to Legionella detection and prevention need to be fulfilled. Among the stakeholders there might be facility managers and FS staff, whose responsibilities include risk management approaches to the maintenance, monitoring, assessment and prevention of contamination of water systems by Legionella (Spagnolo et al., 2013). Some hospitals employ external FM/FS, others operate in-house. To manage tasks properly their roles and duties need to be evident.

Ongoing research will contribute to the common understanding of certain topics for all stakeholders involved in the process.

\section{Methods}

\subsection{Search strategy}

Fig. 2 is an illustration of the incremental search, selection and analysis strategy used to locate publications relevant for a research project. There are three major steps to analysing an abstract once publications have been located in journals and journal databases. Initially the top most relevant 20 abstracts are identified from a set of more than 100 established peer reviewed publications. A final step identifies the top 10 principal reference articles.

\subsection{Literature search}

Initially, literature was searched and articles were collected during November 2015 to February 2016. The data was collected using the Scopus (www.scopus.com), Europe PMC (http://europepmc. org/), Elsevier (https://www.elsevier.com/) and Emerald (www. emeraldinsight.com/) citation databases of peer-reviewed literature using a number of search terms. A total of 13 keyword clusters were defined (see below) and a search was performed using the Boolean operator 'OR':
1. Legionella
2. LD (Legionnaires' Disease)
3. Healthcare, health care
4. Hospital
5. Environment
6. Facilities, facility
7. Water, water system, water distribution system
8. Waterborne
9. Nosocomial, HAI, hospital/healthcare/health care acquired infection
10. Prevention
11. Surveillance
12. Risk, risk assessment, risk management
13. Stakeholder

Where practical, variations or abbreviations of terms were checked (i.e. 2, 3, 6 and 9) or grouped to a meaningful cluster (i.e. 7, 12). No restrictions were made in terms of language, country or date of publication. A total amount of 177 publication titles and corresponding abstracts resulted. The titles and abstracts were obtained 


\section{Abstracts - number of keywords counts}

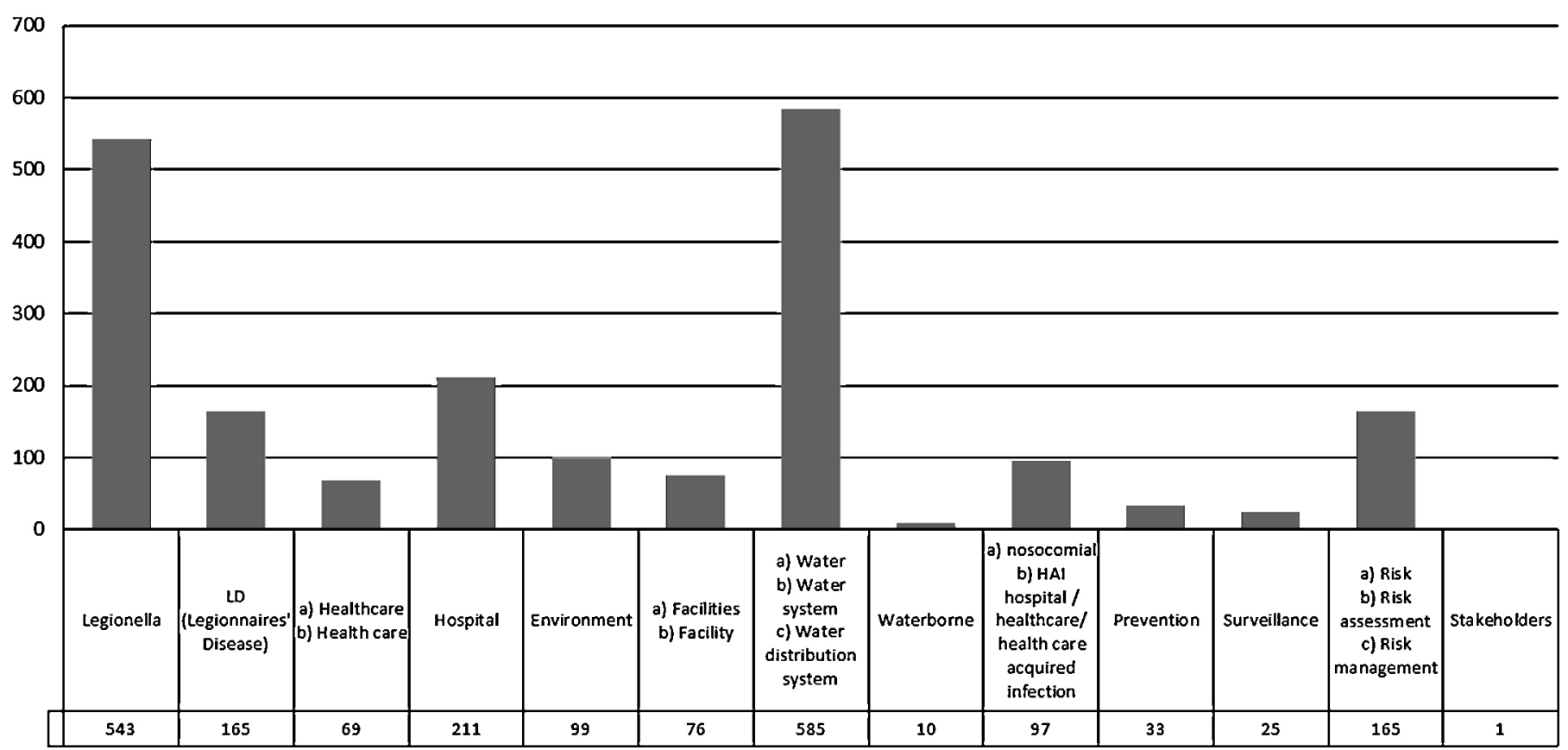

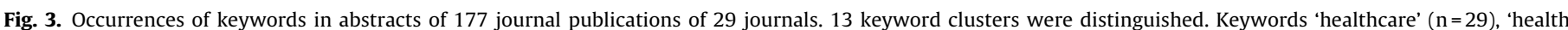

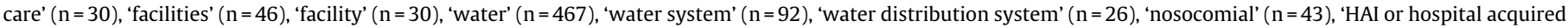

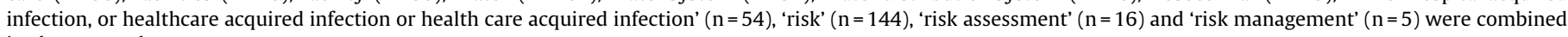
in clusters as shown.

for those publications that seemed to be relevant to the scope of the research as outlined (Fig. 1).

\subsection{Selection of journals}

From the set of 177 articles obtained during literature search, appropriate journals were chosen on the basis of the four main research dimensions (Legionella, hospital, risk management, FM/built environment). The impact rating of a journal was not considered a selection criterion. The different fields of interest were found to be covered by 29 different journals, which consider (built) environmental, constructional, FM and managerial issues as well as epidemiological, microbiological, technical, water system, and non-medical issues. In an alphabetic order, these journals are:

- American Journal of Infection Control (Am. J. Infect. Control)

- Applied and Environmental Microbiology (Appl. Environ. Microbiol.)

- Clinical Infectious Diseases (Clin. Infect. Dis.)

- Clinical Microbiology and Infection (Clin. Microbiol. Infect.)

- Current Opinion in Infectious Diseases (Curr. Opin. Infect. Dis.)

- Emerging Infectious Diseases (Emerg. Infect. Dis.)

- Engineering, Construction and Architectural Management (Engineering, Construction and Architectural Management)

- Environmental Science and Technology (Environ. Sci. Technol.)

- Environmental Technology (Environ. Technol.)

- Epidemiology and Infection (Epidemiol. Infect.)

- Eurosurveillance (Euro Surveill.)

- Facilities (Facilities)

- Health Facilities Management (Health Facilities Management)

- Infection Control and Hospital Epidemiology (Infect. Control Hosp. Epidemiol.)

- International Journal of Hygiene and Environmental Health (Int. J. Hyg. Environ. Health)
- Journal of Clinical Microbiology (J. Clin. Microbiol.)

- Journal of Facilities Management (Journal of Facilities Management)

- Journal of Hospital Infection (J. Hosp. Infect.)

- Journal of Infection (J. Infect.)

- Journal of Infectious Diseases (J. Infect Dis.)

- Journal of Preventive Medicine and Hygiene (J. Prev. Med. Hyg.)

- Lancet Infectious Diseases (Lancet Infect. Dis.)

- Pathogens (Pathogens)

- Public Health (Public Health)

- Reviews in Medical Microbiology (Rev. Med. Microbiol.)

- Science of the Total Environment (Sci. Total Environ.)

- The Lancet (The Lancet)

- Water Environment Research (Water Environ. Res.)

- Water Research (Water Res.)

\subsection{Selection criteria for publications to be considered for analysis}

The search strategy focused on both journal articles and reviews. The publications selected were required to have a title, an abstract and a text body in the main publication. For each publication selected a specific search was performed. 116 Publications met the criteria and were included for analysis; 61 publications failed to meet all criteria.

The following publication types were excluded from the analysis:

Letters to the editor, secondary articles, abstracts of presentations or poster abstracts, abstracts only, announcements for codes and standards, questions to the author, 'newdesk' communications, commentaries, reports.

The following types of publication were included in the analysis:

Journal articles, major articles, short articles, supplement articles, reviews, critical reviews, book reviews, short 
Table 1

Rank list of top 20 most relevant articles. All publications were selected according to the occurrence of the three principal keywords 'Legionella', 'hospital' and 'water' in the abstract. The presence of the principal keyword(s) was tested by logic $\mathrm{y} / \mathrm{n}$. Each publication contained the 3 principal keywords. The second criterion for ordering was the publication date, with more recent publications placed above older ones. Column 2 indicates the sum of counts of these three principal keywords in the abstract. Columns 3 and 4 show the type of publication and the reference. (See the list of references at the end of this paper.).

\begin{tabular}{lrll}
\hline Rank & $\begin{array}{l}\text { Principal keywords } \\
\text { count }\end{array}$ & Type of publication & Reference \\
\hline 1 & 14 & major article & Kruse et al. (2016) \\
2 & 15 & major article & Demirjian et al. (2015) \\
3 & 12 & journal article & Baron et al. (2014) \\
4 & 11 & original article & Casini et al. (2014) \\
5 & 11 & original article & Cristina et al. (2014) \\
6 & 9 & review & Cateau et al. (2014) \\
7 & 17 & review & Spagnolo et al. (2013) \\
8 & 17 & original article & Sydnor et al. (2012) \\
9 & 13 & journal article & Allen et al. (2012) \\
10 & 13 & original article & Haupt et al. (2012) \\
11 & 9 & journal article & Cristino et al. (2012) \\
12 & 8 & short report & Higa et al. (2012) \\
13 & 7 & brief report & Marchesi et al. (2012) \\
14 & 16 & review article & Lin et al. (2011b) \\
15 & 9 & review article & Lin et al. (2011a) \\
16 & 5 & journal article & Marchesi et al. (2011) \\
17 & 16 & major article & Ditommaso et al. (2010) \\
18 & 9 & journal article & Borella et al. (2010) \\
19 & 10 & original article & Palmore et al. (2009) \\
20 & 10 & journal article & Napoli et al. (2009) \\
\hline & & &
\end{tabular}

communications, original research, research papers, concise communications, research notes, brief reports.

\subsection{Selection process for analysis of abstracts}

The selection process was conducted in three consecutive steps.

\subsubsection{Step 1}

First, the title and abstract of all 116 publications, which met the inclusion criteria for analysis, were assessed and scanned for the occurrence of any of the keywords from the 13 keyword clusters. Each keyword was counted both in the title and in the abstract. Two rank lists were compiled, according to the occurrence of the keywords. One list considered the total counts of the keywords in the abstract, the other those in the title.

Fig. 3 summarises the total counts of the keywords occurring in the abstracts of all 116 selected publications.

\subsubsection{Step 2}

In the second selection step, three principal keywords 'Legionella', 'hospital' and 'water' - were identified as a result of the total counts of keywords in the abstract. Those three words were used most frequently in the abstracts. A search applying the Boolean operator 'AND' was performed in all 116 publications. Those 20 abstracts with the most hits were ranked using 'publication date' as the secondary criterion. Where a rank position was shared by two or more publications, recent publications had a higher priority than older ones in direct comparison. On the one hand this procedure avoided shared ranks, on the other hand the most recent publications seem to reflect the tendencies of Legionella prevention in a more up-to-date context

Two rank lists were compiled based on the analysis of the abstracts. One rank list refers to single counts, the other to cumulative counts of the three key words.

Criterion used to sort papers in the rank list for single counts was the presence of the three principal keywords; tested by logic $\mathrm{y} / \mathrm{n}$. Each of the keywords present in the abstract was counted once.
Table 2

Rank list of top 20 most relevant articles. All publications were selected according to the occurrence of the three principal keywords 'Legionella', 'hospital', 'water' in the abstract. The total count of the principal keyword(s) was considered. The second criterion for ordering was the publication date, with more recent publications placed above older ones. Column 2 indicates the sum of the counts of the three principal keywords in the abstract. Columns 3 and 4 show the type of publication and the reference. (See the list of references at the end of this paper.).

\begin{tabular}{llll}
\hline Rank & $\begin{array}{l}\text { Principal } \\
\text { keywords } \\
\text { count }\end{array}$ & Type of publication & Reference \\
\hline 1 & 45 & journal article & \\
2 & 38 & abstract publication & Kool et al. (1999) \\
3 & 38 & Finney et al. (2008) \\
4 & 32 & journal article & O'Neill and Humphreys (2005) \\
5 & 25 & journal article & Rodríguez-Martínez et al. (2015) \\
6 & 25 & journal article & Lasheras et al. (2006) \\
7 & 24 & journal article & Ozerol et al. (2006) \\
8 & 22 & journal article & Huang et al. (2010) \\
9 & 21 & book review & Shelly (2002) \\
10 & 20 & journal article & Oberdorfer et al. (2008) \\
11 & 20 & journal article & van der Kooij et al. (2005) \\
12 & 19 & journal article & Rivera et al. (2007) \\
13 & 18 & journal article & Arvand et al. (2011) \\
14 & 18 & original article & Boccia et al. (2006) \\
15 & 17 & review & Spagnolo et al. (2013) \\
16 & 17 & original article & Sydnor et al. (2012) \\
17 & 17 & review & Sabria and Yu (2002) \\
18 & 16 & journal article & McCoy et al. (2012) \\
19 & 16 & review & Lin et al. (2011b) \\
20 & 16 & major article & Ditommaso et al. (2010) \\
\hline & & &
\end{tabular}

The Boolean operator 'AND' was then applied to rank the list of the 20 publications.

Criterion used to sort papers considering cumulative counts was the occurrence of all three principal keywords - 'Legionella', 'hospital' and 'water' - in the abstract. The total count of the principal keywords was then compiled.

\subsubsection{Step 3}

In a third step, the top 10 principal reference articles were identified considering the publications in both rankings from step 2. For this purpose, the abstracts of the corresponding publications were ranked using 'publication date' as the secondary criterion. Duplicates were omitted so that each publication only appeared once. Cumulative counts of occurring keywords were admitted. The sum of the words from all 13 keyword cluster counts was calculated. Where a rank position was shared, recent publications were preferred to older ones, for the same reasons as mentioned in step 2.

\section{Results}

Rank lists were compiled based on the analysis of the abstracts. We found that the 20 papers with the greatest number of total counts of keywords in abstracts met at least two of the three principal keywords. Papers selected on the basis of the presence of keywords in the title are no longer considered, but only papers selected on the basis of the presence of keywords in abstracts.

\subsection{Rank list 1}

This is a rank list of the top 20 most relevant articles by presence of the three principal keywords (Table 1).

\subsection{Rank list 2}

This is a rank list of the top 20 most relevant articles by the total counts of the principal keywords (Table 2). 


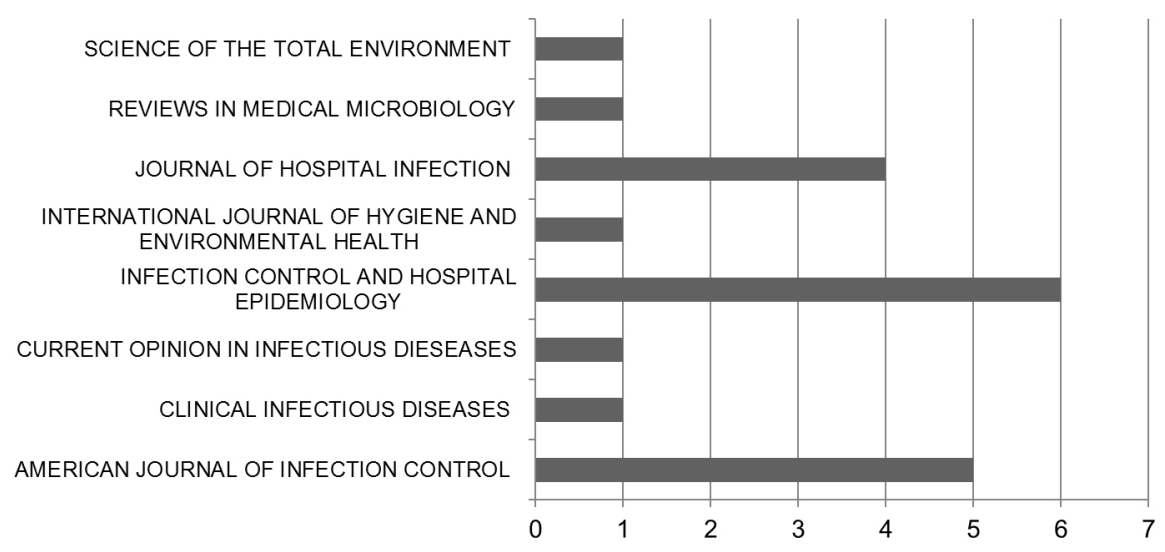

Fig. 4. Frequency of sources from the 20 journal publications which were compiled in the rank list shown in Table 1.

Each of the two rank lists (rank list 1 and rank list 2) is followed by a corresponding figure (Figs. 4 and 5), which indicate the frequency of sources of the 20 journal publications. It gives a rough estimate in which journals the publications were mainly found in.

\subsection{Rank list 3}

This is a rank list of the top 10 principal reference articles. All publications contained in the rank lists 1 and 2 (Tables 1 and 2) were selected and abstracts were analysed according to the occurrence of all the keywords from the initial 13 keyword clusters.

The rank list from step 3 is followed by a figure (Fig. 6) which indicates the frequency of sources of the 10 journal publications, providing a rough estimate of which journals the publications were mainly found in.

\section{Discussion}

Rank lists were compiled to identify the relevant literature for the given research project. The lists present appropriate literature and designate the 20 most relevant articles and the 10 principal research articles based on certain search and analysis criteria. The criteria were chosen to identify relevant literature that considers issues relating to four dimensions, namely Legionella, hospital, risk management, FM/built environment.

The literature search and analysis included 29 different journals which cover topics relevant to the given research project. From the perspective of the research, to which this short literature review and analysis will contribute, the keywords are essential for a comprehensive, interdisciplinary literature search, with two exceptions: 'waterborne' and 'stakeholder'. The last term in particular was underrepresented in the search. It is interesting the term 'stakeholder', which was taken to refer to decision-makers responsible for certain areas, was not found more than once. However, the design and contextual framework of the ongoing research project show, managerial and organisational issues concerning Legionella and water systems in hospitals must not be neglected.

With respect to the methodology of this bibliographic research, the interconnected perspective of water systems, Legionella and hospitals seems to be underrepresented in the literature in the field of the built environment and FM. This may be evidenced by the rank lists of Tables 1-3, in which no journal of either FM or built environment appeared. Admittedly, the selection of 29 different journals was made under the authors' criteria of including journals of different research areas such as represented by the journals in the Methods Section '2.3. Selection of journals'. The selection was thought to match best the four dimensions of research set out by the framework for the research project as outlined in the introduction.

Underlying the methodical approach presented here, selection criteria for publications to be considered for analysis were expected to having a title, an abstract and a main text body. Although some rather interesting publications on Legionella management have been letters to the editor or reports, they were excluded, because they did not meet the criteria. To qualify the content and the relevance of a publication searched for a certain field of interest, the text category or the structure of the text may be of minor importance.

Additional sources than those 29 journals presented here can be ascribed to bear representative literature for FM or the built

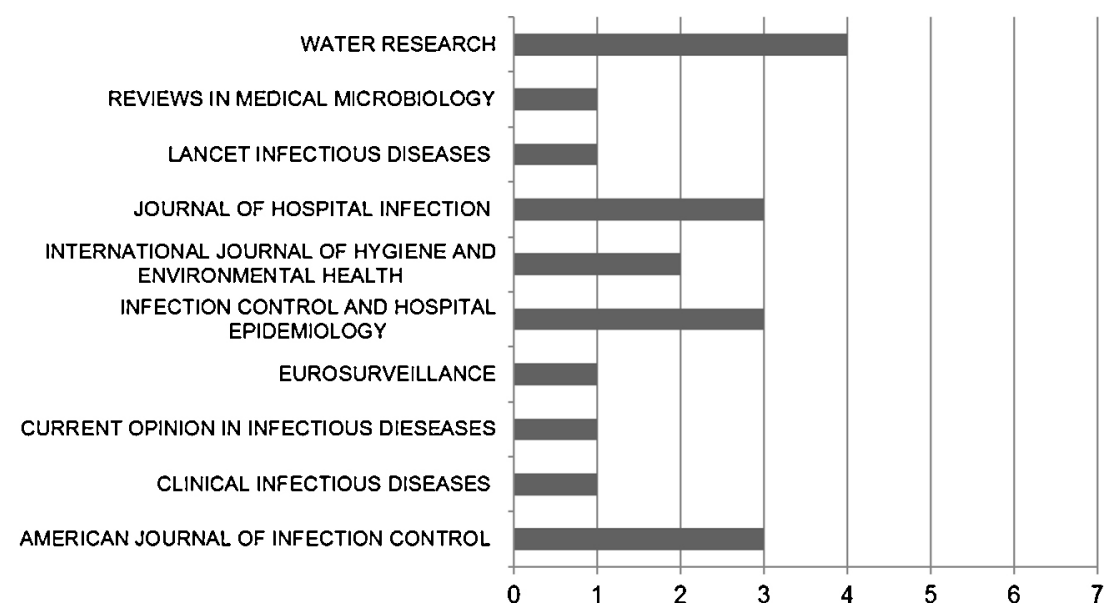

Fig. 5. Frequency of sources from the 20 journal publications which were compiled in the rank list shown in Table 2. 


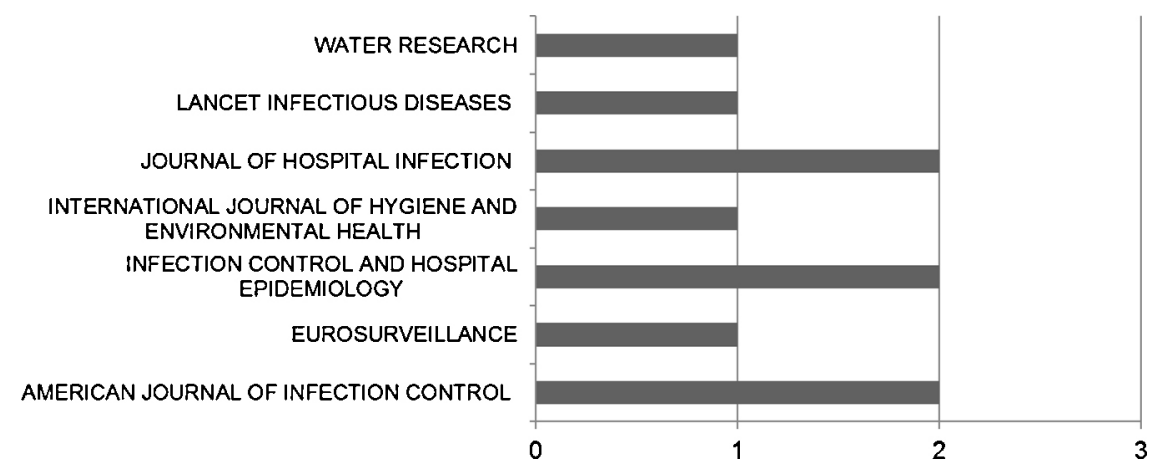

Fig. 6. Frequency of sources from the 10 journal publications which were compiled in the rank list shown in Table 3 .

Table 3

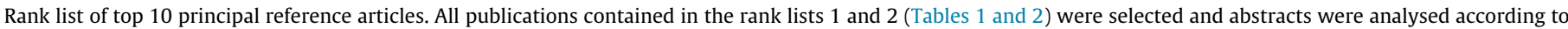

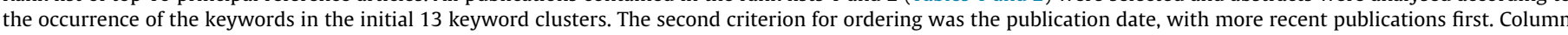

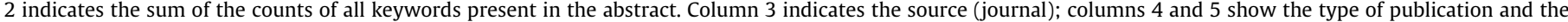
reference. (See the list of references at the end of this paper.).

\begin{tabular}{|c|c|c|c|c|}
\hline Rank & 13 keyword clusters count & Journal & Type of publication & Reference \\
\hline 1 & 61 & Infection Control and Hospital Epidemiology & journal article & Kool et al. (1999) \\
\hline 2 & 54 & Journal Of Hospital Infection & review & O'Neill and Humphreys (2005) \\
\hline 3 & 46 & American Journal Of Infection Control & abstract publication & Finney et al. (2008) \\
\hline 4 & 37 & Infection Control And Hospital Epidemiology & original article & Boccia et al. (2006) \\
\hline 5 & 32 & International Journal Of Hygiene And Environmental Health & journal article & Mathys et al. (2008) \\
\hline 6 & 30 & American Journal Of Infection Control & journal article & Lasheras et al. (2006) \\
\hline 7 & 30 & Eurosurveillance & journal article & Arvand et al. (2011) \\
\hline 8 & 27 & Lancet Infectious Diseases & review & Sabria and Yu (2002) \\
\hline 9 & 25 & Water Research & journal article & Rodríguez-Martínez et al. (2015) \\
\hline 10 & 25 & Journal Of Hospital Infection & journal article & Ozerol et al. (2006) \\
\hline
\end{tabular}

environment, too. Such are for example the 'Journal of Construction Engineering and Management', 'Facilities Management Journal', 'Property Management', 'Building Operating Management', 'Facility Maintenance Decisions' or 'Health Facilities Management Magazine'. In this study they were not considered. It might be correct that the identified 13 keyword clusters would have given more hits than those in the 29 journals selected by the authors. It may also be argued that only a limited number of FM or built environment journals were included. But focusing on only FM or issues of the built environment would be a new perspective for deeper analysis. In addition, the selections made were found to pay tribute to the interdisciplinary demands of Legionella prevention in an adequate intensity.

But in spite of the potential of FM and built environment-related issues towards topics of Legionella prevention at present, the majority of publications concerning risk management of water systems in hospitals focus fields of core-disciplines in HC (i.e. articles with medical content). Nevertheless, non-core-disciplines (e.g. FM or FS) play also important roles in serving hospitals and their environment. Especially when thinking about maintenance, the operating of systems, or regarding in-depth knowledge of technical systems. Maybe keywords like 'disinfection', 'pipes', 'stagnation' and 'maintenance' may have resulted in more FM-specific articles in the rank lists.

\section{Conclusion}

This article is a good example of what can happen, when collaboratively determining keywords that origin from different disciplines while they are deemed to meet a specific research context. Some of the terms originated more from the technical side; others came from the field of HC or from management disciplines. Maybe a common understanding about the wording or the importance of some words preferred to others can be a motivator to tackle interdisciplinary topics - such as risk management of Legionella in hospitals - with an interdisciplinary perspective.

Nevertheless our proposed literature review strategy can be useful in practice to systematically gather comprehensive information by focusing on certain keywords in titles and abstracts. Yet it must be admitted, that omitting specific sources of information (journals, text types) or the omission of certain keywords may lead to unsatisfactory search results. Selection must be considered carefully, context-specifically and to a given main-focus.

Risk management may be an important field in FM and FS. Both serve the built environment. Thus, research in the field of risk management and prevention of Legionella in water systems of hospitals needs an integrated approach. Research in this specific area of risk management needs, at least in certain parts, more weight to the perspectives of facility managers and other persons serving responsibly for the built environment.

\section{Acknowledgements}

The authors wish to thank Zurich University of Applied Sciences (ZHAW), Department Life Sciences and Facility Management, Institute of Facility Management and Liverpool John Moores University (LJMU), Faculty of Engineering and Technology, Department of the Built Environment for supporting junior scientists in their research fields of hygiene and risk management in built environment.

\section{References}

Allen, J.G., Myatt, T.A., MacIntosh, D.L., Ludwig, J.F., Minegishi, T., Stewart, J.H., Connors, B.F., Grant, M.P., McCarthy, J.F., 2012. Assessing risk of health care-acquired Legionnaires' disease from environmental sampling: the limits of using a strict percent positivity approach. Am. J. Infect. Control 40, 917-921, http://dx.doi.org/10.1016/j.ajic.2012.01.013.

Arvand, M., Jungkind, K., Hack, A., 2011. Contamination of the cold water distribution system of health care facilities by Legionella pneumophila: do we know the true dimension? Euro Surveill., 16 (pii = 19844). 
Baron, J.L., Peters, T., Shafer, R., MacMurray, B., Stout, J.E., 2014. Field evaluation of a new point-of-use faucet filter for preventing exposure to Legionella and other waterborne pathogens in health care facilities. Am. J. Infect. Control 42, 1193-1196.

Boccia, S., Laurenti, P., Borella, P., Moscato, U., Capalbo, G., Cambieri, A., Amore, R., Quaranta, G., Boninti, F., Orsini, M., Branca, G., Fadda, G., Romano Spica, V., Ricciardi, G., 2006. Prospective 3-Year surveillance for nosocomial and environmental Legionella pneumophila: implications for infection control. Infect. Control Hosp. Epidemiol. 27, 459-465, http://dx.doi.org/10.1086/ 503642.

Borella, P., Bargellini, A., Marchesi, I., Rovesti, S., Stancanelli, G., Scaltriti, S., Moro, M., Montagna, M.T., Tatò, D., Napoli, C., Triassi, M., Montegrosso, S., Pennino, F., Zotti, C.M., Ditommaso, S., Giacomuzzi, M., 2010. Prevalence of anti-legionella antibodies among Italian hospital workers. J. Hosp. Infect. 69, 148-155, http:// dx.doi.org/10.1016/j.jhin.2008.03.004.

Casini, B., Buzzigoli, A., Cristina, M.L., Spagnolo, A.M., Giudice, P., Del Brusaferro, S. Poscia, A., Moscato, U., Valentini, P., Baggiani, A., Privitera, G., 2014. Long-term effects of hospital water network disinfection on Legionella and other waterborne bacteria in an Italian University Hospital. Infect. Control Hosp. Epidemiol 35, 293-299 http://www.jstor.org/stable/10.1086/675280.

Cateau, E., Delafont, V., Hechard, Y., Rodier, M.H., 2014. Free-living amoebae: what part do they play in healthcare-associated infections? J. Hosp. Infect. 87 131-140, http://dx.doi.org/10.1016/j.jhin.2014.05.001.

Cristina, M.L., Spagnolo, A.M., Casini, B., Baggiani, A., Giudice, P., Del Brusaferro, S., Poscia, A., Moscato, U., Perdelli, F., Orlando, P., 2014. The impact of aerators on water contamination by emerging gram-negative opportunists in At-Risk Hospital Departments. Infect. Control Hosp. Epidemiol. 35, 122-129 http:// www.jstor.org/stable/10.1086/674863.

Cristino, S., Legnani, P.P., Leoni, E., 2012. Plan for the control of Legionella infections in long-term care facilities: role of environmental monitoring. Int. J. Hyg. Environ. Health 215, 279-285, http://dx.doi.org/10.1016/j.ijheh.2011.08.007.

Demirjian, A., Lucas, C.E., Garrison, L.E., Kozak-Muiznieks, N.A., States, S., Brown, E.W., Wortham, J.M., Beaudoin, A., Casey, M.L., Marriott, C., Ludwig, A.M., Sonel, A.F., Muder, R.R., Hicks, L.A., 2015. The importance of clinical surveillance in detecting legionnaires' disease outbreaks: a large outbreak in a hospital with a Legionella disinfection system-Pennsylvania, 2011-2012. Clin. Infect. Dis. 60 1596-1602, http://dx.doi.org/10.1093/cid/civ153.

Ditommaso, S., Giacomuzzi, M., Gentile, M., Moiraghi, A.R., Zotti, C.M., 2010. Effective environmental sampling strategies for monitoring Legionella spp. contamination in hot water systems. Am. J. Infect. Control 38, 344-349, http:/ dx.doi.org/10.1016/j.ajic.2009.09.016.

EN, 2006. BS EN 15221-1: 2006 Facility Management. Terms and Definitions. European Standard. British Standard Institution, London.

Finney, J., Witherell, L.E., Rodriquez, A., 2008. Abstract: controlling Legionella through use of an on-site monochloramine generator: a hospital's five year follow-up after an outbreak. Am. J. Infect. Control 36, E101-E102, http://dx.doi. org/10.1016/j.ajic.2008.04.114.

Gerber, N., Läuppi, V., 2015. Service Catalogue for Non-medical Support Services in Hospitals (LekaS) SN EN 15221-4: adapted, expanded and commented branch specifically. in: Zurich University of Applied Sciences (ZHAW), Institute of Facility Management (IFM), Research Group Hospitality Management and Consumer Science. Prof. Dr. Susanne Hofer (Ed.). Zurich-Waedenswil.

Haupt, T.E., Heffernan, R.T., Kazmierczak, J.J., Nehls-Lowe, H., Rheineck, B., Powell, C., Leonhardt, K.K., Chitnis, A.S., Davis, J.P., 2012. An outbreak of legionnaires disease associated with a decorative water wall fountain in a hospital. Infect. Control Hosp. Epidemiol. 33, 185-191.

Higa, F., Koide, M., Haroon, A., Haranaga, S., Yamashiro, T., Tateyama, M., Fujita, J., 2012. Legionella pneumophila contamination in a steam towel warmer in a hospital setting. Hosp. Infect. 80, 259-261, http://dx.doi.org/10.1016/j.jhin. 2011.12.011.

Hoebe, C.J., Kool, J.L., 2000. Control of Legionella in drinking-water systems. Lancet 355, 2093-2094, http://dx.doi.org/10.1016/S0140-6736(00)02374-6.

Huang, S.-W., Hsu, B.-M., Wu, S.-F., Fan, C.-W., Shih, F.-C., Lin, Y.-C., Ji, D.-D., 2010. Water quality parameters associated with prevalence of Legionella in hot spring facility water bodies. Water Res. 44, 4805-4811, http://dx.doi.org/10. 1016/j.watres.2010.07.063.

Hungenberg, H., 2014. Strategisches Management in Unternehmen: Ziele-Prozesse-Verfahren. Springer Fachmedien, Wiesbaden.

Kool, J.L., Bergmire-Sweat, D., Butler, J.C., Brown, E.W., Peabody, D.J., Massi, D.S., Carpenter, J.C., Pruckler, J.M., Benson, R.F., Fields, B.S., 1999. Hospital characteristics associated with colonization of water systems by Legionella an risk of nosocomial legionnaires' disease: a cohort study of 15 hospitals. Infect. Control Hosp. Epidemiol. 20, 798-805, http://dx.doi.org/10.1086/501587.

Kruse, E.-B., Wehner, A., Wisplinghoff, H., 2016. Prevalence and distribution of Legionella spp. in potable water systems in Germany, risk factors associated with contamination, and effectiveness of thermal disinfection. Am. J. Infect. Control., http://dx.doi.org/10.1016/j.ajic.2015.10.025.
Lasheras, A., Boulestreau, H., Rogues, A.-M., Ohayon-Courtes, C., Labadie, J.-C. Gachie, J.-P., 2006. Influence of amoebae and physical and chemical characteristics of water on presence and proliferation of Legionella species in hospital water systems. Am. J. Infect. Control 34, 520-525, http://dx.doi.org/10. 1016/j.ajic.2006.03.007.

Leiblein, T.W., Tucker, M., Ashall, M., Lee, S.B., Gollnisch, C., Hofer, S., 2015. Duty holders for Legionella prevention in healthcare organisations: The implications for Facility Management. Poster first published at ESGLI Conference, Third Annual Scientific Conference, London, 16.-17.09.2015. Poster Session 4 Microbial Ecology, Prev. Published in: Waterline-J. Water Manag. Soc. 36.

Lin, Y.E., Stout, J.E., Yu, V.L., 2011a. Controlling Legionella in hospital drinking water: an evidence-based review of disinfection methods. Infect. Control Hosp. Epidemiol. 32, 166-173, http://dx.doi.org/10.1086/657934.

Lin, Y.E., Stout, J.E., Yu, V.L., 2011b. Prevention of hospital-acquired legionellosis. Curr. Opin. Infect. Dis. 24, 350-356, http://dx.doi.org/10.1097/QCO. 0b013e3283486c6e.

Marchesi, I., Marchegiano, P., Bargellini, A., Cencetti, S., Frezza, G., Miselli, M., Borella, P., 2011. Effectiveness of different methods to control Legionella in the water supply: ten-year experience in an Italian university hospital. J. Hosp. Infect. 77, 47-51, http://dx.doi.org/10.1016/j.jhin.2010.09.012.

Marchesi, I., Cencetti, S., Marchegiano, P., Frezza, G., Borella, P., Bargellini, A., 2012. Control of Legionella contamination in a hospital water distribution system by monochloramine. Am. J. Infect. Control 40, 279-281, http://dx.doi.org/10.1016/ j.ajic.2011.03.008.

Mathys, W., Stanke, J., Harmuth, M., Junge-Mathys, E., 2008. Occurrence of Legionella in hot water systems of single-family residences in suburbs of two German cities with special reference to solar and district heating. Int. J. Hyg. Environ. Health 211, 179-185, http://dx.doi.org/10.1016/j.ijheh.2007.02.004.

McCoy, W.F., Downes, E.L., Leonidas, L.F., Cain, M.F., Sherman, D.L., Chen, K., Devender, S., Neville, M.J., 2012. Inaccuracy in Legionella tests of building water systems due to sample holding time. Water Res. 46, 3497-3506, http://dx.doi. org/10.1016/j.watres.2012.03.062.

Napoli, C., Iatta, R., Fasano, F., Marsico, T., Montagna, M.T., 2009. Variable bacterial load of Legionella spp. in a hospital water system. Sci. Total Environ. 408, 242-244.

O'Neill, E., Humphreys, H., 2005. Surveillance of hospital water and primary prevention of nosocomial legionellosis: what is the evidence? J. Hosp. Infect. 59, 273-279, http://dx.doi.org/10.1016/j.jhin.2004.09.031.

Oberdorfer, K., Müssigbrodt, G., Wendt, C., 2008. Genetic diversity of Legionella pneumophila in hospital water systems. Int. J. Hyg. Environ. Health 211 , 172-178, http://dx.doi.org/10.1016/j.ijheh.2007.04.003.

Ozerol, I.H., Bayraktar, M., Cizmeci, Z., Durmaz, R., Akbas, E., Yildirim, Z., Yologlu, S. 2006. Legionnaire's disease: a nosocomial outbreak in Turkey. J. Hosp. Infect. 62, 50-57, http://dx.doi.org/10.1016/j.jhin.2005.04.018.

Palmore, T.N., Stock, F., White, M., Bordner, M., Michelin, A., Bennett, J.E., Murray, P.R., Henderson, D.K., 2009. A cluster of cases of nosocomial legionnaires disease linked to a contaminated hospital decorative water fountain. Infect. Control Hosp. Epidemiol. 30, 764-768, http://dx.doi.org/10.1086/598855.

Rivera, J.M., Aguilar, L., Granizo, J.J., Vos-Arenilla, A., Giménez, M.-J., Aguiar, J.-M., Prieto, J., 2007. Isolation of Legionella species/serogroups from water cooling systems compared with potable water systems in Spanish healthcare facilities. J. Hosp. Infect. 67, 360-366, http://dx.doi.org/10.1016/j.jhin.2007.07.022.

Rodríguez-Martínez, S., Sharaby, Y., Pecellín, M., Brettar, I., Höfle, M., Halpern, M. 2015. Spatial distribution of Legionella pneumophila MLVA-genotypes in a drinking water system. Water Res. 77, 119-132, http://dx.doi.org/10.1016/j. watres.2015.03.010.

Sabria, M., Yu, V.L., 2002. Hospital-acquired legionellosis: solutions for a preventable infection. Lancet Infect. Dis. 2, 368-373.

Shelly, M., 2002. Legionella. Clin. Infect. Dis. 35, 905.

Spagnolo, A.M., Cristina, M.L., Casini, B., Perdelli, F., 2013. Legionella pneumophila in healthcare facilities. Rev. Med. Microbiol. 24, 70-80 http://dx.doi.org/10. 1097/MRM.0b013e328362fe66.

Sydnor, E.R.M., Bova, G., Gimburg, A., Cosgrove, S.E., Perl, T.M., Maragakis, L.L. 2012. Electronic-eye faucets Legionella species contamination in healthcare settings. Infect. Control Hosp. Epidemiol. 33, 235-240, http://dx.doi.org/10. $1086 / 664047$

van der Kooij, D., Veenendaal, H.R., Scheffer, W.J.H., 2005. Biofilm formation and multiplication of Legionella in a model warm water system with pipes of copper, stainless steel and cross-linked polyethylene. Water Res. 39, 2789-2798, http://dx.doi.org/10.1016/j.watres.2005.04.075.

Völker, S., Schreiber, C., Kistemann, T., 2016. Modelling characteristics to predict Legionella contamination risk-surveillance of drinking water plumbing systems and identification of risk areas. Int. J. Hyg. Environ. Health 219, 101-109, http://dx.doi.org/10.1016/j.ijheh.2015.09.007. 